\title{
Mandatory vaccination for health care workers: an analysis of law and policy
}

\author{
Colleen M. Flood SJD, Bryan Thomas SJD, Kumanan Wilson MD
}

— Cite as: CMAJ 2021 February 8;193:E217-20. doi: 10.1503/cmaj.202755; early-released January 19, 2021

CMAJ Podcasts: author interview at www.cmaj.ca/lookup/doi/10.1503/cmaj.202755/tab-related-content

W ith the approval of vaccines for severe acute respiratory syndrome coronavirus 2 (SARS-CoV-2), the vaccination of Canada's health care workers who come in direct contact with patients is a top priority. ${ }^{1}$ The important question arises of whether governments, public health care organizations and private actors, such as the companies that own and administer long-term care facilities, should consider taking the controversial step of making SARS-CoV-2 vaccination mandatory, whether by direct regulation or under terms of employment. The rationale for taking such a step is that vaccination will protect individual health care workers, and the patients for whom they care, from acquiring SARS-CoV-2. Preventing coronavirus disease 2019 (COVID-19) in those who are vaccinated will also ensure that the health workforce does not become dangerously depleted. However, mandatory vaccination policies may be challenged. Historically, policies on mandatory influenza vaccination have been contested under labour law, and in theory might be challenged under human rights law and the Canadian Charter of Rights and Freedoms. ${ }^{2}$ We discuss legal precedents emerging from attempts to mandate influenza vaccines for health care workers and whether they translate to the context of the SARS-CoV-2 vaccination, and explain how both governments and individual employers (e.g., public hospitals or private longterm care homes) may legally justify SARS-CoV-2 vaccinations of health care workers.

\section{Does case law on influenza vaccination apply to SARS-CoV-2 vaccination?}

Much of the extant law relating to influenza vaccination for health care workers comes from labour arbitrator decisions (not courts) that resolve disputes between different employers (e.g., public hospitals) and health care workers' unions. Agreements reached in the labour-law context do not limit choices by Canadian governments or employers with respect to SARS-CoV-2 vaccinations. For example, an agreement reached between the British Columbia government and nurses in December 2019, leaving it to individual nurses whether to have the influenza vaccination, does not mean that going forward, the British Columbia government, public hospitals or long-term care homes are similarly limited in requiring SARS-CoV-2 vaccinations. Moreover, law developed in

\section{KEY POINTS}

- An effective vaccine provided to all health care workers in Canada will protect both the health workforce and patients, reducing the overall burden of coronavirus disease 2019 on services and ensuring adequate personnel to minister to people's health needs through the pandemic.

- Provincial governments should put in place rules for mandatory vaccination of health care workers that cut across all public and private settings, and should not leave this to the discretion of individual employers.

- If individual employers were to require vaccination among their staff, the legality of these mandates would likely be determined via labour law that considers the "reasonableness" of the employer's directive, as is evident from case law related to mandatory influenza vaccination.

- Government mandates for the vaccination of health care workers may be challenged under the Canadian Charter of Rights and Freedoms, but these challenges, on the extant evidence, likely will not succeed if provisions are made for those who cannot receive the vaccination because of underlying health issues and for those who object to vaccination on bona fide religious or conscientious objection grounds.

- Challengers may argue that health care workers have the right to wear personal protective equipment (PPE) in lieu of receiving vaccination, which means that governments must support vaccine surveillance and keep abreast of emerging evidence of the effectiveness and safety of the various severe acute respiratory syndrome coronavirus 2 (SARS-CoV-2) vaccines relative to evidence of the effectiveness of PPE in reducing transmission of SARS-CoV-2.

the context of influenza vaccinations will not be applied indiscriminately to the COVID-19 context: law is adaptive to changing scientific evidence. An example of relevant evidence is that, compared with the various influenza strains, SARS-CoV- 2 is both more transmissible and has a higher case fatality rate. ${ }^{3,4}$

The relatively short time frame of SARS-CoV-2 vaccine development (less than a year) is also relevant; for some this may heighten concerns about safety and effectiveness of the vaccines, yet it bears mentioning that different influenza vaccines are administered every year. ${ }^{5}$ As we write, it is also not clear whether emerging vaccines will prevent transmission of all SARS-CoV-2 
strains or whether trial estimates will be borne out in nontrial settings. The evidence on safety, effectiveness, reduction in infectivity and duration of immunity for the different vaccines will evolve as vaccination programs roll out. All these factors will be considered when assessing legal issues. Because the evidence is limited regarding the extent to which SARS-CoV-2 vaccination programs prevent transmission, one question relevant to legal disputes is whether other measures, such as masking, could be sufficiently effective and obviate the need to mandate vaccination.

\section{What are the relevant laws pertaining to mandatory vaccination of health care workers?}

The law's handling of vaccination requirements for health care workers depends in part on the decision-maker involved (Box 1). It matters, for example, whether such policies are imposed by employers (e.g., hospitals or long-term care homes) or by governments directly. Government actions are open to Charter challenge; for example, under s. 7 of the Canadian Charter of Rights and Freedoms, which protects an individual's right to life, liberty or security of the person. On the other hand, actions by nongovernmental actors are subject to the Charter much more rarely and only when acting "governmentally" (i.e., directly carrying out government policy). The Charter would not apply to a privately financed long-term care facility acting on its own to require health care worker vaccination, although employer mandates could be contested via labourlaw challenges. However, if a provincial government required all health care workers to be vaccinated and a private facility wanted to enforce this for its employees, a Charter challenge is possible (but unlikely to succeed, as explained below).

In our view, provincial governments should not leave the decision of whether to require a SARS-CoV-2 vaccine to the variability of choices made by different employers, but should set clear rules for all public and private health care settings. Indeed, the perils of excluding private actors like long-term care facilities from the ambit of clear government rules regarding infection control became blisteringly clear during the first wave of the COVID-19 pandemic, and the same mistake should be avoided when it comes to SARS-CoV-2 vaccination requirements.

\section{Labour-law challenges to employer mandates to vaccinate or mask}

Most of the legal challenges to mandatory vaccination of health care workers for influenza have arisen in the context of labour law (specifically labour arbitrations), and those decisions have limited precedential value vis-à-vis the question of whether Canadian governments could require health care workers to be vaccinated for SARS-CoV-2. Still, these previous decisions may be of relevance if provincial governments fail to promulgate clear rules for all settings, as we advocate below, and instead leave the decision up to the discretion of individual employers. If so, the question then turns effectively on whether a requirement to vaccinate for SARS-CoV-2 constitutes a reasonable exercise of management rights.

The extant labour law focuses on claims that requirements to vaccinate or stay at home (without pay), or to vaccinate or mask, are an unreasonable unilateral exercise of employer rights. In making the case for unreasonableness, unions have raised scientific arguments, such as challenging the efficacy of masks and arguing that influenza is unlikely to be transmitted by asymptomatic carriers (an argument that likely cannot be supported for SARS-CoV-2). Unions have buttressed the case for unreasonableness by arguing that influenza vaccination requirements breach Charter rights (e.g., the s. 7 rights to liberty and security of the person), privacy laws and human rights (e.g., protections against discrimination on the basis of physical disability) - even when it is not clear that the Charter would apply to the actions of the health care facility.

How labour law treats a challenge to a vaccination mandate may also turn on the forcefulness of the mandate. For example, in St. Peter's Health System v. Canadian Union of Public Employees Local 778, the employer categorically required vaccination as

Box 1: Legal pathways for challenging mandatory vaccination of health care workers

Labour-law context

- Does the vaccination requirement reflect a governmental act (e.g. an order by the Minister of Health)? If yes, see Charter law context (right column).

- Is the vaccination requirement reasonable?

- What are the potential harms from COVID-19?

- What is the evidence of the effectiveness of vaccines in responding to those harms?

- What is the evidence of risk from vaccines to health care workers?

- Should health care workers have the option to wear PPE instead?

- Is there evidence that vaccines are more effective than PPE?

- Are there pragmatic considerations (e.g., cost, scarcity, enforcement difficulties) that make PPE an unreasonable alternative?

\section{Charter Canadian of Rights and Freedoms law context}

- Has government acted (e.g., by order, law, regulation) to require health care worker vaccination?

- Does the order constitute forced medical treatment (engaging Charter rights to liberty or security of the person)?

- Are the consequences of refusing so severe as to negate meaningful choice?

- Charter precedent strongly suggests that "economic rights" are not protected, and this includes the right to practise a profession.

- Is the vaccination requirement overly broad?

- Would a more permissive policy of "vaccinate or use PPE" achieve the government's objective?

- Are there pragmatic considerations (e.g., cost, scarcity, enforcement difficulties) that make PPE an unreasonable alternative?

- Could the policy be more carefully tailored (e.g., imposed only at facilities that have experienced outbreaks)? 
a condition of service during an influenza outbreak, requiring employees who refused vaccination to stay home without pay. After a wide-ranging review of Charter and common-law precedents, the arbitrator found that the policy infringed upon the right to security of the person - "forced medical treatment ... is an assault if there is not consent" 6 - and deemed the policy unenforceable. Legal scholars reviewing overall trends in this area have claimed that St. Peter's is an outlier, noting that arbitrators in most cases "have concluded that policies prohibiting [unvaccinated] health care workers from working during facility outbreaks are consistent with collective agreements, given the weight of evidence that such policies are connected with the health care organization's interest in patient safety." ${ }^{2}$ However, the arbitrator found a broader requirement to vaccinate or mask (outside of the context of an outbreak) to be an unreasonable exercise of management power in St. Michael's Hospital \& The Ontario Hospital Assoc. v. the Ontario Nurses' Association, with the arbitrator concluding that evidence supporting masking of health care workers as an effective means to protect patients from the flu influenza was "insufficient, inadequate and completely unpersuasive."7

Both the St. Peter's and St. Michael's Hospital examples show that the reasonableness of mandates depends on several contextual factors. In the case of the COVID-19 pandemic, given the protective effect of properly used personal protective equipment (PPE) and evolving evidence suggesting that mask-wearing reduces spread of SARS-CoV- $2,{ }^{8}$ an important question is whether employers can reasonably require employees to be vaccinated even in situations where employees state they will wear PPE or take other appropriate precautions.

\section{Charter challenges to government mandates}

Clear government rules as to when and where health care workers must be vaccinated do create a greater risk of a Charter challenge than mandates from individual employers. However, there is scope within the Charter for governments to defend a mandatory vaccination policy for health care workers, provided appropriate exemptions are made because of pre-existing health conditions and for bona fide religious and conscientious objections (scientific skepticism about vaccination is unlikely to receive accommodation).

To be clear, a government rule for health care workers who interact directly with patients to be vaccinated or stay at home would not force any person to be vaccinated; governmentimposed, forced vaccination would be highly vulnerable to a Charter challenge. Instead, it would impose an economic cost for health care workers who refused vaccination without bona fide objection. Such an order for health care workers to vaccinate or stay at home would not, in our view, constitute forced medical treatment and thus would not be prima facie contrary to s. 7 of the Charter, despite potentially inflicting substantial economic hardship on health care workers who refuse to receive the vaccine. The Charter has not historically protected economic interests and specifically the "right to work." If challengers were somehow successful in arguing that there was a prima facie breach of s. 7 of the Charter, they would still have to establish that the deprivation was not in accordance with the "principles of fundamental justice." Finally, governments will have the opportunity to defend the mandate on the grounds that it was proportionate in the context of the COVID-19 pandemic (s. 1).

\section{Can health care workers insist that PPE alone would sufficiently protect them and their patients?}

The question of whether PPE alone provides sufficient protection is germane to the disposition of challenges both in the labourlaw context and to a Charter challenge.

As discussed above, although controversial, a province or an employer could justify a policy of requiring health care workers to either vaccinate for SARS-CoV-2 or stay at home without pay. Any court or labour arbitrator would need to acknowledge the COVID19 pandemic-related risks - specifically the relatively high infection and morbidity and mortality rates associated with COVID-19, higher risks for vulnerable patients, risks unique to health care workers, and the dangers to patients more broadly if an already stretched health care workforce is diminished by many becoming ill with COVID-19. To be constitutionally permissible, exemptions to any mandate would have to be made for those with pre-existing health conditions that preclude vaccination and those with genuine religious or conscientious objections. ${ }^{9}$ As vaccines are first introduced, Canada's health care workers will be required to continue to wear appropriate PPE even when vaccinated. But could health care workers demand that they be given the option to wear PPE (or, conceivably, wear a mask), in lieu of vaccination? Whether a health care worker could successfully contest a mandate for vaccination by arguing that PPE alone is sufficient will depend upon several factors and is contingent on evidence still emerging.

One potentially relevant factor will be differences in health care settings: it may be possible to claim that PPE and physical distancing measures are feasible and sufficient to safeguard patients in the psychiatry setting, for example. Another relevant factor may be evidence as to the expense and difficulty of procuring PPE and, pragmatically, whether it is used appropriately so as to effectively reduce the risk of acquiring SARS-CoV-2 infection for both health care workers and their patients. The efficacy of different vaccines outside of clinical trials may be relevant as well; e.g., evidence as to how well the vaccine protects those with specific conditions who were not included among trial participants. Because, from a legal standpoint, the case for a vaccine mandate rests in part on protecting vulnerable patients and health care workers, a critical factor will be relative evidence of the effectiveness of vaccination and PPE in reducing SARS-CoV-2 transmission. Here the evidence is somewhat uncertain: randomized controlled trials of the SARS-CoV-2 vaccines have not yet yielded full results on the extent to which SARS-CoV-2 vaccines prevent transmission of the virus to others, but the expectation is that there will be at least some degree of reduced infectivity. ${ }^{10,11}$ Follow-up from these trials should provide data on this important question. We would suggest that any provincial government could argue, applying the precautionary principle, that requiring vaccination of health care workers without clear evidence of reduced viral transmission is justifiable given the unique severity of the COVID-19 pandemic. Moreover, a vaccination mandate could 
also be justified, at least until the pandemic is well under control, on the grounds that it is essential to maximize the health care workforce available to treat patients with COVID-19. If phase 3 trials provide data suggesting reduction in infectivity, the argument in favour of vaccination mandates will be considerably strengthened, as a similar level of evidence would not exist for PPE.

\section{What other considerations are important?}

Given that evidence of the safety and effectiveness of many vaccines is still emerging, future scenarios may see policies being justifiable for some SARS-CoV-2 vaccines and not others, if trials and surveillance show widely differing effectiveness and safety. This could give rise to situations in which health care workers could agree to a policy if provided with a safer or more effective vaccine, to which an employer may not have access.

Adequate recourse for those who may be harmed by mandatory vaccination policies are important. We applaud the recent announcement of a no-fault vaccine compensation scheme and await the implementation of the program. ${ }^{12}$ Although not a cureall, it does provide some security for health care workers obligated to vaccinate pursuant to carrying out their vital work.

\section{Conclusion}

The topic of mandatory vaccinations is a highly charged one. The COVID-19 pandemic has presented many scientific, legal and policy challenges, and mandatory vaccination policies for health care workers may present more. An effective vaccine provided to health care workers will protect both the health workforce and patients, reducing the overall burden of COVID-19 on services and ensuring adequate personnel to minister to people's health needs through the pandemic. Evidence may well emerge to show that vaccination will reduce SARS-CoV-2 transmission to vulnerable patients.

Provincial and territorial governments should set clear rules for vaccination of health care workers across public and private settings and not leave this task to individual employers. Although a mandate that health care workers must be vaccinated, or else stay home without pay, could be the subject of a Charter challenge, governments should be able to successfully defend such a challenge. To be defensible, any vaccination mandate must have exemptions for those who cannot be vaccinated or have bona fide religious or conscience objections. A more complex question is whether a health care worker could claim that it is sufficient to wear PPE rather than be vaccinated, which means that governments should carefully and repeatedly evaluate evidence of the effectiveness of PPE relative to the known efficacy of available vaccines. Further, the federal government must fund and support a robust postmarket vaccine surveillance system across Canada, to better understand the efficacy of vaccines in the real world (e.g., on populations not included in the trials), case severity and adverse events, and they should support further research on the impact of vaccines on transmission. ${ }^{13}$ Such evidence will be essential to understanding the real impact of different vaccines in protecting health care workers and patients, allowing provincial governments to calibrate vaccination policies for the health workforce accordingly.

\section{References}

1. Ismail SJ, Zhao L, Tunis MC, et al.; National Advisory Committee on Immunization. Key populations for early COVID-19 immunization: preliminary guidance for policy. CMAJ 2020;192:E1620-32.

2. Gruben V, Reed AS, McGreer A. Health care workers, mandatory influenza vaccination policies and the law. CMAJ 2014;186:1076-80.

3. Petersen E, Koopmans M, Go U, et al. Comparing SARS-CoV-2 with SARS-CoV and influenza pandemics. Lancet Infect Dis 2020;20:e238-44.

4. Piroth L, Cottenet J, Mariet A-S, et al. Comparison of the characteristics, morbidity, and mortality of COVID-19 and seasonal influenza: a nationwide, populationbased retrospective cohort study. Lancet Respir Med 2020 Dec. 17 [Epub ahead of print]. doi: 10.1016/S2213-2600(20)30527-0.

5. COVID-19 vaccines: no time for complacency. Lancet 2020;396:1607.

6. St. Peter's Health System v. Canada Union of Public Employees, Local 778 (Flu vaccination grievance) [2002] 106 L.A.C. (4th) 170.

7. St. Michael's Hospital v. Ontario Nurses' Association, CANLII 82519.

8. Brainard J, Jones NR, Lake IR, et al. Community use of face masks and similar barriers to prevent respiratory illness such as COVID-19: a rapid scoping review. Euro Surveill 2020;25:2000725.

9. Thomas B, Flood CM. Eliminating religious and philosophical exemptions: the next step in Ontario's campaign against vaccine hesitancy. Healthc Policy 2020;16:14-20.

10. Mandavilli A. Here's why vaccinated people still need to wear a mask. The New York Times 2020 Dec. 8, updated 2020 Dec. 9. Available: www.nytimes. com/2020/12/08/health/covid-vaccine-mask.html (accessed 2021 Jan. 6).

11. Vaccines and Related Biological Products Advisory Committee meeting presentation. mRNA-1273: sponsor briefing document addendum, Dec. 17, 2020. Silver Spring (MD): Food and Drug Administration; 2020. Available: www.fda.gov/ media/144453/download (accessed 2021 Jan. 5).

12. Government of Canada Announces pan-Canadian vaccine injury support program [news release]. Public Health Agency of Canada; modified 2020 Dec. 10. Available: www.canada.ca/en/public-health/news/2020/12/government-of-canada -announces-pan-canadian-vaccine-injury-support-program.html (accessed 2021 Jan. 11).

13. Canadian National Vaccine Safety Network (CANVAS): What is CANVAS? Halifax: Canadian Immunization Research Network. Available: cirnetwork.ca/network/ national-ambulatory-network/ (accessed 2021 Jan. 6).

Competing interests: Kumanan Wilson is Chief Executive Officer of CANImmunize. No other competing interests were declared.

This article has been peer reviewed.

Affiliations: Faculty of Law (Flood, Thomas), Common Law Section, and Department of Medicine (Wilson), School of Epidemiology and Public Health, University of Ottawa, Ottawa, Ont; Bruyère Research Institute (Wilson), Ottawa, Ont; Ottawa Hospital Research Institute (Wilson), Ottawa, Ont.

Contributors: All of the authors contributed to the conception and design of the work, drafted the manuscript, revised it critically for important intellectual content, gave final approval of the version to be published and agreed to be accountable for all aspects of the work.

Content licence: This is an Open Access article distributed in accordance with the terms of the Creative Commons Attribution (CC BY-NCND 4.0) licence, which permits use, distribution and reproduction in any medium, provided that the original publication is properly cited, the use is noncommercial (i.e., research or educational use), and no modifications or adaptations are made. See: https://creativecommons.org/ licenses/by-nc-nd/4.0/

Funding: This research is funded in part by the COVID-19 Immunity Task Force, launched by the Government of Canada in collaboration with Canadian Institutes of Health Research.

Disclaimer: Kumanan Wilson is married to an employee of CMAJ, who was not involved with the editorial decision-making process for this article.

Correspondence to: Bryan Thomas, bryan.thomas@uottawa.ca 